\title{
Levantamento de seio maxilar modificado utilizando a técnica do travesseiro. Relato de caso clínico
}

\author{
Modified Sinus Lifting using the pillow technique. Clinical case report \\ Levantamiento del seno maxilar modificado mediante la técnica de la almohada. Reporte de caso \\ clínico
}

Recebido: 28/04/2021 | Revisado: 05/05/2021 | Aceito: 07/05/2021 | Publicado: 22/05/2021

Jeferson Luis de Oliveira Stroparo

ORCID: https://orcid.org/0000-0003-1094-530X

Universidade Positivo, Brazil

E-mail: jef_stroparo@hotmail.com

Geraldo Fernando Stroparo

ORCID: https://orcid.org/0000-0002-3563-9176 Consultório Privado, Brasil

E-mail: jeferson.stroparo@gmail.com

Felipe Rychuv Santos

ORCID: https://orcid.org/0000-0001-7738-6229

Universidade Positivo, Brazil

E-mail: ferychuv@gmail.com

Carmen Lucia Mueller Storrer

ORCID: https://orcid.org/0000-0002-1188-8848 São Leopoldo Mandic, Brazil

E-mail: carmen.storrer@gmail.com

João César Zielak

ORCID: https://orcid.org/0000-0003-3393-3491

Universidade Positivo, Brazil

E-mail: jzielak2@gmail.com

Tatiana Miranda Deliberador

ORCID: https://orcid.org/0000-0003-4076-4905 Instituto Latino Americano de Pesquisa e Ensino Odontológico, Brazil

E-mail: tdeliberador@gmail.com

\begin{abstract}
Resumo
Devido à necessidade da reabilitação com implantes dentários, a cirurgia de levantamento do seio maxilar é descrita como uma técnica segura, neste relato de caso demonstramos uma técnica modificada de levantamento de seio maxilar, a técnica do travesseiro, na qual é confeccionado um travesseiro com uma membrana absorvível preenchida com enxerto ósseo. No momento cirúrgico é utilizada a técnica da janela lateral com deslocamento da membrana de Schneider e inserção do travesseiro. Como resultado clínico foi observado uma quantidade satisfatória de ganho ósseo no pós-operatório de 11 meses. Com essa técnica é possível obter um menor tempo cirúrgico devido à necessidade apenas da preparação do leito receptor, visto que o travesseiro é confeccionado previamente ao ato cirúrgico, além de uma nova manobra para a proteção do biomaterial em casos de perfurações da membrana de Schneider diminuindo a chance de complicações pós-operatórias.
\end{abstract}

Palavras-chave: Enxertia óssea; Membranas; Regeneração óssea.

\begin{abstract}
Due to the need for rehabilitation with dental implants, maxillary sinus lifting surgery is described as a safe technique, in this case report we demonstrate a modified maxillary sinus lifting technique, the pillow technique, in which a pillow is made with a absorbable membrane filled with bone graft. At the time of surgery, the side window technique with displacement of the Schneider membrane and insertion of the pillow is used. As a clinical result, a satisfactory amount of bone gain was observed in the 11-month postoperative period. With this technique, it is possible to obtain a shorter surgical time due to the need only for the preparation of the receiving bed, since the pillow is made prior to the surgical act, in addition to a new maneuver for the protection of the biomaterial in cases of perforations of the Schneider membrane decreasing the chance of postoperative complications.
\end{abstract}

Keywords: Bone grafting; Membranes; Bone regeneration. 


\begin{abstract}
Resumen
Debido a la necesidad de rehabilitación con implantes dentales, la cirugía de elevación del seno maxilar se describe como una técnica segura, en este reporte de caso demostramos una técnica de elevación del seno maxilar modificada, la técnica de la almohada, en la cual se hace una almohada con una membrana absorbible rellena de injerto óseo. En el momento de la cirugía se utiliza la técnica de ventana lateral con desplazamiento de la membrana de Schneider e inserción de la almohada. Como resultado clínico, se observó una cantidad satisfactoria de ganancia ósea en el período posoperatorio de 11 meses. Con esta técnica, es posible obtener un menor tiempo quirúrgico debido a la necesidad solo de la preparación de la cama receptora, ya que la almohada se realiza antes de la cirugía, además de una nueva maniobra para la protección del biomaterial en casos de perforaciones de la membrana de Schneider que disminuyen la posibilidad de complicaciones posoperatorias.
\end{abstract}

Palabras clave: Injerto óseo; Membranas; Regeneración ósea.

\title{
1. Introduçãa
}

A perda de dentes posteriores pode ocorrer devido a vários fatores, o que consequentemente acarreta na pnematização do seio maxilar, gerando uma atrofia do osso alveolar que acaba prejudicando a reabilitação com implantes dentários (Silva et al., 2016; Testori et al., 2020).

Devido à necessidade da reabilitação com implantes dentários, a cirurgia de levantamento do seio maxilar é descrita como uma técnica segura, nas quais podem ser utilizados biomateriais autógenos, alógenos, xenógenos e sintéticos (Manfro et al., 2014; Stroparo et al., 2021). Contudo, mesmo com o biomaterial autógeno sendo considerado o atual padrão ouro, os biomateriais xenógenos, que geralmente tem origem bovina ou eqüina, apresentam boa biocompatibilidade e uma morfologia semelhante a do osso humano, tendo várias vantagens, como baixa taxa de absorção, menos morbidade ao paciente, uma disponibilidade ilimitada, as quais são associadas a altas taxas de sucesso, pois esse biomaterial serve de arcabouço para formação de osso maduro(Riben \& Thor 2012; Manfro et al., 2014; Stroparo et al., 2021).

Existem duas técnicas distintas para fazer o levantamento do seio maxilar, a técnica atraumática e traumática. A técnica com osteótomos (atraumática) é indicada quando existe pelo menos de 5 a $6 \mathrm{~mm}$ de osso alveolar presente entre a crista óssea e assoalho do seio maxilar, sendo possível ganhar de 4 a $8 \mathrm{~mm}$ de altura óssea, sendo suficiente para instalação de implantes (Silva et al., 2016). A segunda técnica é a da janela lateral (traumática), a qual é indicada quando ocorre uma maior pneumatização do seio maxilar, sendo necessário o preenchimento do seio maxilar com biomateriais (Silva et al., 2016).

Uma das complicações trans-operatórias mais comum é a perfuração da membrana de Schneider, tendo prevalência de 0 a 58,3\% e com média de 19,5\%, sendo que outras, são complicações pós-operatórias, como a exposição de enxerto e da membrana, infecção ou formação de seroma (Silva et al., 2016; Testoriet al., 2020).

Dentre as técnicas relatadas para tratar as perfurações da membrana incluem sutura, uso de membranas de colágeno, uso de fibrina rica em plaquetas, celulose regenerada oxidada e lâminas de osso lamelar liofilizado (Pikos, 2008).

As membranas absorvíveis de colágeno, apresentam boa biocompatibilidade, possibilitando uma rápida vascularização da área enxertada, a qual é essencial para a maturação do osso (Saravanan et al., 2013; Pang et al., 2014; Atef et al., 2020; Piovezana et al., 2020;).Atualmente muitos estudos também investigaram a combinação de biomateriais com a membrana de Fibrina rica em plaqueta e leucócitos (L-PRF), pois devido aos seus fatores de crescimento foi observada uma maior vascularização devido a uma melhor angiogênese, ocasionando uma melhor e mais acelerada cicatrização de tecidos duros e moles (Dohan, et al., 2006; Fardin et al., 2010; Wu et al., 2012; Zhang et al., 2012; Pichotano et al., 2019, Tchemra et al., 2021).

A técnica de levantamento de seio maxilar da janela lateral é uma técnica segura e confiável, sendo amplamente descrita na literatura, apresentando resultados previsíveis (Wallace \& Froum, 2003; Gassling et al., 2013; Esposito et al., 2014), entretanto o nosso objetivo é apresentar uma nova opção cirúrgica. 


\section{Metodologia}

Este artigo é um relato de caso, abordado de forma descritiva e qualitativa, onde o objetivo do presente trabalho é relatar uma técnica de levantamento de seio maxilar modificado, usando a técnica do travesseiro. $\mathrm{O}$ termo de consentimento livre e esclarecido foi assinado pelo paciente.

\section{Relato de Caso}

Paciente AEW de 70 anos, sexo masculino compareceu a Universidade para instalação de implantes dentários, após exame clínico e avaliação da imagem tomográfica foi planejado a cirurgia de levantamento de seio maxilar bilateral (Figura 1 A, B C), sendo que optamos por utilizar a técnica do travesseiro do lado direito, e do lado esquerdo a técnica traumática convencional.

Figura 1 - Imagem tomográfica inicial.
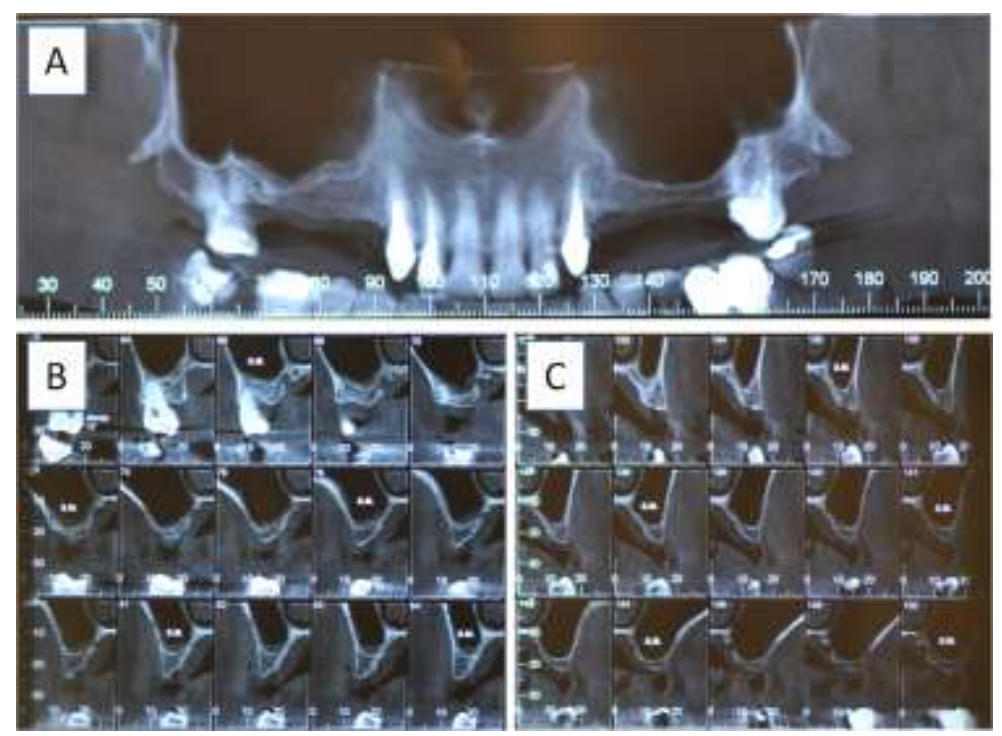

A) Imagem radiográfica panorâmica da tomográfica inicial; B) Imagem tomográfica dos cortes 62 ao 84 mostrando o seio maxilar direito antes do enxerto ser realizado; C) Imagem tomográfica dos cortes 132 ao 150 mostrando o seio maxilar esquerdo antes do enxerto ser realizado. Fonte: Autores

O paciente relatou no dia da anamnese utilizar prótese cardíaca do tipo marca-passo, então foi realizada profilaxia antibiótica com 2 gramas de amoxicilina 1hora antes do procedimento.

Previamente ao inicio da cirurgia o travesseiro deve ser feito e para isso é necessário, biomaterial xenogênico, sendo que neste relato de caso foi utilizado o BioOss ${ }^{\circledR}$ (Geistlich Pharma, Suiça) (Figura 2A), uma membrana absorvível, sendo utilizada neste caso a GenDerm 30mm x20mm(Baumer, Mogi Mirim- São PauloBrazil)(Figura 2B)e fio de sutura reabsorvível, sendo utilizado o fio de sutura poliglactina 910 5-0 (Bioline Fios Cirurgicos, Anápolis-GO Brazil). Para a confecção do travesseiro, a membrana foi dobrada (Figura 2C) e suturada com o fio reabsorvível (Figura 2D), deixado um dos lados sem suturar para poder preencher com o biomaterial (Figura 2E), a membrana agora em formato de travesseiro foipreenchida com biomaterial, que deve ficar bem compactado (Figura 1F) para não ficar espaços vazios (Figura 2G), e então foi realizada a última sutura completando a confecção do travesseiro (Figura 2H). 
Figura 2 - Confecção do travesseiro.
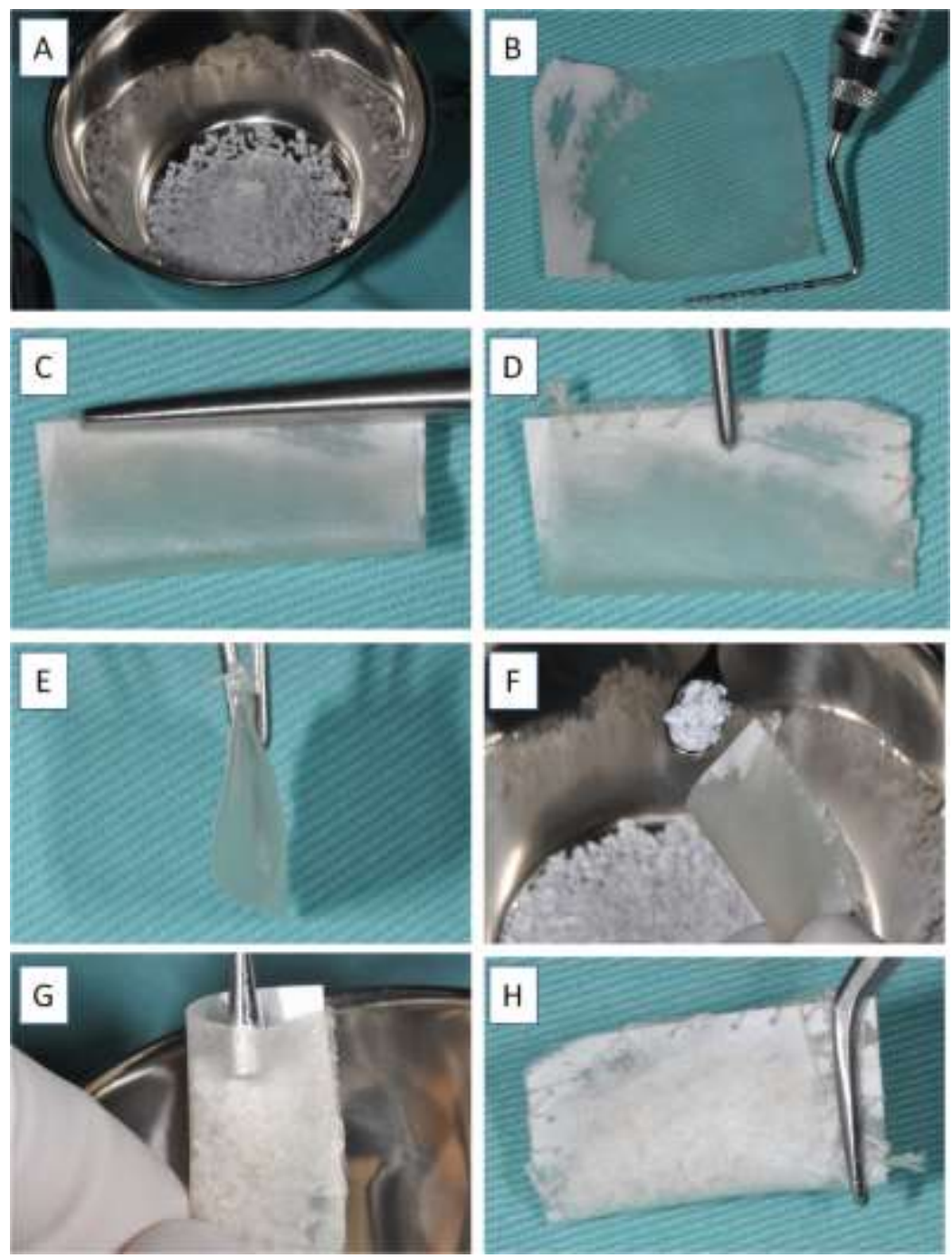

A) Biomaterial Xenogênico BioOss $®$; B) Membrana absorvível GenDerm ${ }^{\circledR} 30 \mathrm{~mm}$ x20mm; C) Membrana dobrada dando forma ao travesseiro; D) Membrana sendo suturada com fio de sutura reabsorvível poliglactina 910 5-0; E) Travesseiro pronto para receber o biomaterial; F) Biomaterial sendo inserido no travesseiro; G) Biomaterial sendo compactado dentro do travesseiro para evitar espaços vagos; H) Travesseiro finalizado pronto para ser utilizado. Fonte: Autores

Para o procedimento cirúrgico foi realizada anestesia infiltrativa com articaína 4\% mais epinefrina 1:100.000, (Articaine DFL, Rio de Janeiro - RJ, Brasil), seguida de incisão sobre a crista óssea e duas incisões relaxantes e rebatimento de um retalho de espessura total (Figura 3A). Para abertura da janela lateral do seio maxilar foi utilizada uma broca esférica diamantada n.8, sob irrigação constante com soro fisiológico (Figura 3B), fazendo a osteotomia até deixar a cortical translúcida (Figura 3C), a membrana de Schneider foi então descolada e elevada com curetas de levantamento de seio ( $\mathrm{N}^{\circ} 1,3,4,5$ e 7,Neodent, Curitiba-PR, Brazil) com muita precisão e cautela, para não ocorrer nenhum rompimento da membrana.

O travesseiro então foi mergulhado em soro fisiológico e introduzido cuidadosamente dentro do seio maxilar (Figura 3D) seguida da complementação com biomaterial (figura 3E), até que o espaço do seio maxilar ficasse totalmente preenchido (Figura 3F), o enxerto foi coberto com uma membrana de L-PRF (Figura 3G), e então foi feita sutura continua festonada e suturas simples nas relaxantes (Figura $3 \mathrm{H}$ ). 
Figura 3 - Levantamento de seio maxilar pela técnica do travesseiro.


A) Incisões e rebatimento do retalho de espessura total expondo a região a ser operada para o levantamento de seio; B) Osteotomia inicial; C) Descolamento e elevação da membrana de Schneider com as curetas de levantamento de seio; D) Travesseiro sendo inserido no seio maxilar; E) Travesseiro inserido totalmente; F) Preenchimento do seio maxilar com biomaterial; G) Membrana de L-PRF cobrindo a área enxertada; H) Sutura continua festonada e suturas simples nas relaxantes

No lado esquerdo foi realizada anestesia infiltrativa com articaína 4\% mais epinefrina 1:100.000, (Articaine DFL, Rio de Janeiro - RJ, Brasil).Nesse lado foi optada a realização da técnica convencional, seguindo a mesma sequência cirúrgica anterior de incisão e rebatimento do retalho (Figura 4A), abertura da janela lateral (Figura 4B), elevação da membrana de Schneider(Figura 4C), preenchimento do seio maxilar com biomaterial e membranas de L-PRF (Figura 4D, E e F), recobrimento do janela do seio com membranas de L-PRF(Figura 4G), seguida de sutura continua festonada e suturas simples nas relaxantes (Figura 4H). 
Figura 4 - Levantamento de seio maxilar pela técnica convencional.
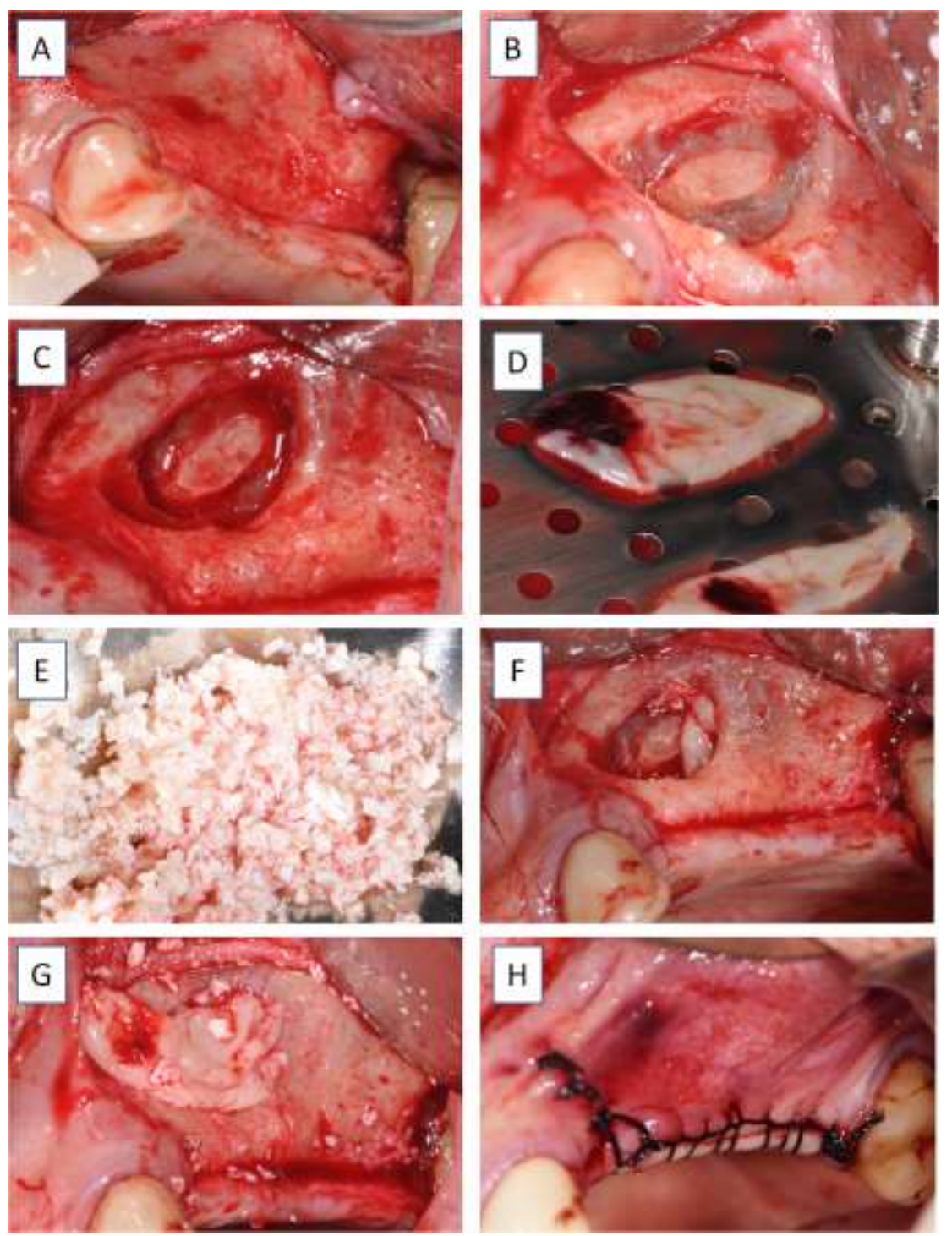

Figura 4- A) Incisão e rebatimento de retalho de espessura total; B) Osteotomia da janela lateral do seio maxilar; C) Elevação da membrana de Schneider; D) Membranas de L-PRF; E) Biomaterial hidratado com I-PRF e membrana de L-PRF picada adicionada ao biomaterial; F) Membrana de L-PRF forrando o seio maxilar; G) Membrana de L-PRF recobrindo e protegendo a área do enxerto; H) Sutura continua festonada e suturas simples nas relaxantes. Fonte: Autores.

Foi prescrito Amoxicilina 875+125 com Clavulanato de Potássio por 14 dias, e Toragesic 10mg sublingual. No acompanhamento e comparação das tomografias observou-se uma quantidade de biomaterial adequada na tomografia com 7 dias de pós operatório (Figura 5A, B, C), e com 11 meses de pós operatório pode-se observar ganho ósseo satisfatório em ambos os lados (Figura 5D, E, F). 
Figura 5 - Imagem tomográfica do pós-operatório de 7 dias e de 11 meses.


Figura 5- A) Imagem radiográfica panorâmica da tomográfica com 7 dias de pós operatório; B) Imagem tomográfica dos cortes 64 ao 78 mostrando o seio maxilar direito com 7 dias de pós operatório; C) Imagem tomográfica dos cortes 127 ao 148 mostrando o seio maxilar esquerdo com 7 dias de pós operatório. D) Imagem radiográfica panorâmica da tomográfica de 11 meses de pós-operatório; E) Imagem tomográfica dos cortes 68,5 ao 89,5 mostrando o seio maxilar direito com de 11 meses de pós-operatório; F) Imagem tomográfica dos cortes 139 ao 160 mostrando o seio maxilar esquerdo com de 11 meses de pósoperatório. Fonte: Autores.

\section{Discussão}

Os biomateriais xenógenos possuem propriedades ostecondutoras, sendo produzidos por meio de processos de purificação em vários estágios, sendo que o biomaterial utilizado no estudo é vastamente relato na literatura como capaz de se integrar ao osso, tendo baixa taxa de reabsorção e altas taxas de sucesso (Manfro et al., 2014; Fadel et al., 2018; Stroparo et al., 2021). Quanto à utilização de membranas de colágeno, elas já são amplamente utilizadas na regeneração óssea guiada, no qual o uso de membranas protege o biomaterial enxertado, ocasionando preservações de enxertos e de alvéolos após extrações (Pang et al., 2014; Fadel et al., 2018; Troiano et al., 2018; Piovezana et al., 2020). 
Tratando-se da cirurgia de levantamento de seio maxilar um quesito importante para é preservação da integridade da membrana de membrana de Schneider, pois com a acomodação adequada do biomaterial existem grandes chances de sucesso, porém a complicação intra-operatória mais comum é a perfuração da membrana de Schneider (Lundgren et al., 2008; Pikos 2008; Srouji et al., 2009).

Segundo Silva et al. (2016) e Testori et al. (2020) quando ocorre essa perfuração sejam por fatores como espessura da membrana Schneider, presença de septos ou a sua perfuração durante a confecção da janela lateral podem ocorrer algumas complicações pós operatórias comosinusite aguda, infecção do biomaterial ou até mesmo o deslocamento do biomaterial para a cavidade sinusal. Pikos (2008), também frisa a importância do reparo dessas perfurações, pois se o enxerto extravasar para a cavidade sinusal pode ocorrer migração para o óstio o que aumenta as chances de infecção.

Uma das vantagens com a técnica do travesseiro inclui que o biomaterial esta dentro de uma membrana e condensado adequadamente, evitando que o mesmo se espalhe pela cavidade sinusal ou que gere outras complicações mesmo em caso de rompimento da membrana. Pode-se salientar também que em caso de grandes perfurações acima de $1,5 \mathrm{~cm}$, o reparo e utilização de diversas técnicas pode se tornar imprevisível e problemática (Pikos, 2008).

Outra vantagem desta técnica é a diminuição do tempo cirúrgico, pois o travesseiro é feito fora da boca, pouco antes do inicio da cirurgia, bastando confeccionar o leito receptor e introduzir o travesseiro com o biomaterial, tendo uma boa eficácia, pois o biomaterial esta bem condensado diminuindo o risco do biomaterial espalhar dentro do leito receptor, uma limitação da técnica é que se o travesseiro for pequeno o enxerto pode ficar mais localizado.

Neste relato de caso também foi utilizada a membrana L-PRF, que de acordo com Liu et al. (2019), libera fatores de crescimento autólogos durante os primeiros 7 dias e diminuindo gradualmente até os 28 dias, isso tem uma boa aplicabilidade pois ela acelera a cicatrização e também melhora a formação óssea no local do enxerto, sendo considerada ótima quando associada aos biomateriais para as cirurgias de levantamento de seio, pois além disso a membrana também auxilia na proteção da área enxertada de possíveis exposições pós operatórias.

\section{Conclusão}

Conclui-se que com a utilização da técnica do travesseiro é possível obter um menor tempo cirúrgico devido à necessidade apenas da preparação do leito receptor, visto que o travesseiro é confeccionado fora da boca, além de uma nova manobra para a proteção do biomaterial em casos de perfurações da membrana de Schneider diminuindo a chance de complicações pós-operatórias. Novos ensaios clínicos devem ser realizados para observar mais efeitos da técnica do travesseiro

\section{Agradecimentos}

Os autores declaram não haver conflito de interesses.

\section{Referências}

Atef, M., Tarek, A., Shaheen, M., Alarawi, R. M., \& Askar, N. (2020). Horizontal ridge augmentation using native collagen membrane vs titanium mesh in atrophic maxillary ridges: Randomized clinical trial. Clin Implant Dent Relat Res. 22(2):156-166. 10.1111/cid.12892

Dohan, D. M., Choukroun, J., Diss, A., Dohan, S. L., Dohan, A. J., Mouhyi, J., \& Gogly, B. (2006). Platelet-rich fibrin (PRF): a second-generation platelet concentrate. Part I: technological concepts and evolution. Oral Surg Oral Med Oral Pathol Oral Radiol Endod, 101(3), e37-e44.

Esposito, M., Felice, P., \& Worthington, H. V. (2014). Interventions for replacing missing teeth: augmentation procedures of the maxillary sinus. Cochrane Database Syst Rev.May 13(5) CD008397. 10.1002/14651858.CD008397.pub2.

Fadel, R. A., Samarani, R., \& Chakar, C. (2018). Guided bone regeneration in calvarial critical size bony defect using a double-layer resorbable collagen membrane covering a xenograft: a histological and histomorphometric study in rats. Oral Maxillofac Surg. 22(2):203-213. 10.1007/s10006-018-0694-x

Fardin, A. C., Jardim, E. C. G., Pereira, F. C., Guskuma, M. H., Aranega, A. M., \& Garcia Júnior, I. R. (2010). Enxerto ósseo em odontologia: revisão de literatura. Innovations Implant Journal, 5(3), 48-52. 
Gassling, V., Purcz, N., Braesen, J.-H., Will, M., Gierloff, M., Behrens, E., Açil, Y., \& Wiltfang, J. (2013). Comparison of two different absorbable membranes for the coverage of lateral osteotomy sites in maxillary sinus augmentation: a preliminary study. Journal of Cranio-Maxillo-Facial Surgery, 41(1), 76-82.

Liu, R., Yan, M., Chen, S., Huang, W., Wu, D., \& Chen, J. (2019) Effectiveness of Platelet-Rich Fibrin as an Adjunctive Material to Bone Graft in Maxillary Sinus Augmentation: A Meta-Analysis of Randomized Controlled Trails. Biomed Res Int.; 2019:7267062. Published 2019 Mar 17. 10.1155/2019/7267062

Lundgren, S., Cricchio, G., Palma, V. C., Salata, L. A., \& Sennerby, L. (2008). Sinus membrane elevation and simultaneous insertion of dental implants: a new surgical technique in maxillary sinus floor augmentation. Periodontology 2000, 47, 193-205. https://doi.org/10.1111/j.1600-0757.2008.00264.x

Manfro, R., Fonseca, F. S., Bortoluzzi, M. C., \& Sendyk, W. R. (2014). Comparative, Histological and Histomorphometric Analysis of Three Anorganic Bovine Xenogenous Bone Substitutes: Bio-Oss, Bone-Fill and Gen-Ox Anorganic. J Maxillofac Oral Surg. 13(4):464-70. 10.1007/s12663-013-0554-z.

Pang, C., Ding, Y., Zhou, H., Qin, R., Hou, R., Zhang, G. \& Hu, K. (2014). Alveolar ridge preservation with deproteinized bovine bone graft and collagen membrane and delayed implants. The Journal of craniofacial surgery, 25(5), 1698-1702

Pichotano, E. C., de Molon, R. S., de Souza, R. V., Austin, R. S., Marcantonio, E., Zandim-Barcelos, D. L. (2019) Evaluation of L-PRF combined with deproteinized bovine bone mineral for early implant placement after maxillary sinus augmentation: A randomized clinical trial. Clin Implant Dent Relat Res. 21(2):253-262. 10.1111/cid.12713.

Pikos, M. A. (2008). Maxillary sinus membrane repair: update on technique for large and complete perforations. Implant Dent. 17(1):24-31. $10.1097 /$ ID.0b013e318166d934

Piovezana, A., Gregorio, D., Paludeto, D. A. de O., Etore, L. de C. D., Guskuma, M. H., \& Maia, L. P. (2020). Uso de Membrana com ou sem Bio-Oss Para Preservação do Alvéolo de Extração: Uma Série de Casos. Research, Society and Development, 9(12), e41991211130. https://doi.org/10.33448/rsdv9i12.11130

Riben, C., \& Thor, A. (2012). The Maxillary Sinus Membrane Elevation Procedure: Augmentation of Bone around Dental Implants without Grafts-A Review of a Surgical Technique.International journal of dentistry, 105483. https://doi.org/10.1155/2012/105483

Saravanan, P., Ramakrishnan, T., Ambalavanan, N., Emmadi, P. \& John, T. L. (2013). Efficacy of guided bone regeneration using composite bone graft and resorbable collagen membrane in Seibert's Class I ridge defects: radiological evaluation. The Journal of oral implantology, 39(4), 455-462.

Silva, L. D., de Lima, V. N., Faverani, L. P., de Mendonça, M. R., Okamoto, R., \& Pellizzer, E. P. (2016). Maxillary sinus lift surgery-with or without graft material? A systematic review. Int J Oral Maxillofac Surg.; 45(12):1570-1576. 10.1016/j.ijom.2016.09.023

Srouji, S., Kizhner, T., Ben David, D., Riminucci, M., Bianco, P., \& Livne, E. (2009). The Schneiderian membrane contains osteoprogenitor cells: in vivo and invitro study. Calcified tissue international, 84(2), 138-145. https://doi.org/10.1007/s00223-008-9202-x

Stroparo, J. L. de O., Weiss, S. G., Fonseca, S. C., Spisila, L. J., Gonzaga, C. C., Oliveira, G. C., Brotto, G. L., Swiech, A. M., Franco, C. R. C., Leão, M. P., Deliberador, T. M., Gabardo, M. C. L., \& Zielak, J. C. (2021). Biomateriais de enxerto ósseo xenogênico não interferem na viabilidade e proliferação de células-tronco de dentes decíduos esfoliados humanos - um estudo piloto in vitro. Research, Society and Development, 10(4), e34410414249. https://doi.org/10.33448/rsd-v10i4.14249

Tchemra, F. G. C., Rezende, M., Morelli, F. M., Medeiros, S. T. C. B., \& Diniz, A. G. (2021). Efetividade do uso da Fibrina Rica em Plaquetas (PRF) no levantamento de seio maxilar: relato de caso. Research, Society and Development, 10(1), e29210111492. https://doi.org/10.33448/rsd-v10i1.11492

Testori, T., Yu, S. H., Tavelli, L., \& Wang, H. L. (2020). Perforation Risk Assessment in Maxillary Sinus Augmentation with Lateral Wall Technique. Int J Periodontics Restorative Dent. 40(3):373-380. 10.11607/prd.4179

Troiano, G., Zhurakivska, K., Lo Muzio, L., Laino, L., Cicciù, M. \& Lo Russo, L. (2018). Combination of bone graft and resorbable membrane for alveolar ridge preservation: A systematic review, meta-analysis, and trial sequential analysis. Journal of periodontology, 89(1), 46-57.

Wallace, S. S., \& Froum, S. J. (2003). Effect of maxillary sinus augmentation on the survival of endosseous dental implants. A systematic review. Ann Periodontol. 8(1):328-43. 10.1902/annals.2003.8.1.328. 